\title{
An early Cambrian fauna of skeletal fossils from the Emyaksin Formation, northern Siberia
}

Artem Kouchinsky, Stefan Bengtson, Sébastien Clausen, and Michael J. Vendrasco

Acta Palaeontologica Polonica 60 (2), 2015: 421-512 doi: http://dx.doi.org/10.4202/app.2012.0004

An assemblage of mineralised skeletal fossils containing molluscs, hyoliths, halkieriids, chancelloriids, tommotiids, lobopodians, paleoscolecids, bradoriids, echinoderms, anabaritids, hyolithelminths, hexactinnelid, and heteractinid sponges is described from the early Cambrian Emyaksin Formation exposed along the Malaya Kuonamka and Bol'shaya Kuonamka rivers, eastern flanks of the Anabar Uplift, northern Siberian Platform. The sampled succession is attributed to the Tommotian-Botoman Stages of Siberia and correlated with Stage 2 of Series 1-Stage 4 of Series 2 of the IUGS chronostratigraphical scheme for the Cambrian. Carbon isotope chemostratigraphy is applied herein for regional correlation. The fauna contains the earliest Siberian and probably global first appearances of lobopodians, paleoscolecids, and echinoderms, and includes elements in common with coeval faunas from Gondwana, Laurentia, and Baltica. For the first time from Siberia, the latest occurrence of anabaritids is documented herein from the Atdabanian Stage. Problematic calcium phosphatic sclerites of Fengzuella zhejiangensis have not been previously known from outside China. The sellate sclerites, Camenella garbowskae and mitral sclerites, C. kozlowskii are unified within one species, C. garbowskae . In addition to more common slender sclerites, Rhombocorniculum insolutum include broad calcium phosphatic sclerites. A number of fossils described herein demonstrate excellent preservation of fine details of skeletal microstructures. Based on new microstructural data, sclerites of Rhombocorniculum are interpreted as chaetae of the type occurring in annelids. A new mollusc Enigmaconus? pyramidalis Kouchinsky and Vendrasco sp. nov. and a hyolith Triplicatella papilio Kouchinsky sp. nov. are described.

Key words: Skeletal fossils, Echinodermata, stratigraphy, Cambrian, Siberia.

Artem Kouchinsky [artem.kouchinsky@nrm.se] and Stefan Bengtson [stefan.bengtson@nrm.se ], Department of Palaeozoology and Nordic Center for Earth Evolution (NordCEE), Swedish Museum of Natural History, Box 50007, SE-104 05

Stockholm, Sweden; Sébastien Clausen [clausen.sebastien@live.fr] UMR8157/7207 CNRS, Université de Lille 1, 59655 Villeneuve d'Ascq, France; Michael J. Vendrasco [mvendrasco@fullerton.edu], Department of Biological Science (MH-282), 
California State University, Fullerton, P.O. Box 6850 Fullerton, CA 92834-6850.

This is an open-access article distributed under the terms of the Creative Commons Attribution License (for details please see creativecommons.org), which permits unrestricted use, distribution, and reproduction in any medium, provided the original author and source are credited.

Fof
Fof
Sull text $(11,976.0 \mathrm{kB})$ 